Article

\title{
CoMn Catalysts Derived from Hydrotalcite-Like Precursors for Direct Conversion of Syngas to Fuel Range Hydrocarbons
}

\author{
Zahra Gholami *(D), Zdeněk Tišler ${ }^{\circledR}$, Romana Velvarská and Jaroslav Kocík \\ Unipetrol Centre of Research and Education, a.s, Areál Chempark 2838, Záluží 1, 43670 Litvínov, Czech Republic; \\ zdenek.tisler@unicre.cz (Z.T.); romana.velvarska@unicre.cz (R.V.); jaroslav.kocik@unicre.cz (J.K.) \\ * Correspondence: Zahra.gholami@unicre.cz; Tel.: +420-471-122-239
}

Received: 8 July 2020; Accepted: 19 July 2020; Published: 22 July 2020

check for updates

\begin{abstract}
Two different groups of CoMn catalysts derived from hydrotalcite-like precursors were prepared through the co-precipitation method, and their performance in the direct production of gasoline and jet fuel range hydrocarbons through Fischer-Tropsch (FT) synthesis was evaluated in a batch autoclave reactor at $240{ }^{\circ} \mathrm{C}$ and $7 \mathrm{MPa}$ and $\mathrm{H}_{2} / \mathrm{CO}$ of 2 . The physicochemical properties of the prepared catalysts were investigated and characterized using different characterization techniques. Catalyst performance was significantly affected by the catalyst preparation method. The crystalline phase of the catalyst prepared using $\mathrm{KOH}$ contained $\mathrm{Co}_{3} \mathrm{O}_{4}$ and some $\mathrm{Co}_{2} \mathrm{MnO}_{4.5}$ spinels, with a lower reducibility and catalytic activity than cobalt oxide. The available cobalt active sites are responsible for the chain growth, and the accessible acid sites are responsible for the cracking and isomerization. The catalysts prepared using $\mathrm{KOH}+\mathrm{K}_{2} \mathrm{CO}_{3}$ mixture as a precipitant agent exhibited a high selectivity of $51-61 \%$ for gasoline $\left(C_{5}-C_{10}\right)$ and $30-50 \%$ for jet fuel $\left(C_{8}-C_{16}\right)$ range hydrocarbons compared with catalysts precipitated by $\mathrm{KOH}$. The CoMn-HTC-III catalyst with the highest number of available acid sites showed the highest selectivity to $C_{5}-C_{10}$ hydrocarbons, which demonstrates that a high Brønsted acidity leads to the high degree of cracking of FT products. The CO conversion did not significantly change, and it was around 35-39\% for all catalysts. Owing to the poor activity in the water-gas shift reaction, $\mathrm{CO}_{2}$ formation was less than $2 \%$ in all the catalysts.
\end{abstract}

Keywords: Fischer-Tropsch; jet fuel; gasoline; CoMn; hydrotalcite-like precursors

\section{Introduction}

The impending depletion of fossil fuel sources and the growing demand for energy resources because of increasing population and economic development have led to new approaches to the production of renewable liquid fuels. X-to-liquid technologies for converting different carbon-containing sources, such as natural gas (GTL), coal (CTL), biomass (BTL), and waste/oil residues (WTL), to liquid fuels have received special attention [1]. Typical transformation processes for the conversion of non-petroleum carbon resources into liquid fuel are shown in Figure 1. Carbonaceous resources are transformed into syngas $\left(\mathrm{H}_{2}+\mathrm{CO}\right)$ through reforming, gasification, or partial oxidation and then converted to a wide range of hydrocarbons. These hydrocarbons are refined to produce final products, including liquefied petroleum gas, gasoline, jet fuel, distillate, diesel, and wax [2]. Fischer-Tropsch (FT) is a well-known process for the catalytic conversion of syngas into higher hydrocarbons and oxygenates, which are finally upgraded to sulfur and aromatic free transportation fuels and chemicals [3-7]. The FT process plays an essential role in the production of sustainable and clean liquid fuels through $\mathrm{CO}$ hydrogenation. The product distribution of the traditional FT process follows the Anderson-Schulz-Flory (ASF) law and can be determined using the value of chain growth probability. 
However, controlling product selectivity for the production of specific hydrocarbons, such as gasoline $\left(C_{5}-C_{10}\right)$, diesel fuel $\left(C_{11}-C_{22}\right)$, or jet fuel $\left(C_{8}-C_{16}\right)$, is extremely challenging $[8,9]$. Several researchers have reported efficient methods for directly synthesizing gasoline, diesel, and jet fuel [8,10-13]. The direct conversion of syngas to liquid fuels through the FT process reduces the demand for refining units, such as hydrocrackers, by increasing the product selectivity of desired liquid hydrocarbons. Different parameters, such as the active phase of the catalyst and its chemical state, physicochemical properties, support, and promoter, considerably influence the catalytic activity and product selectivity in the FT reaction. Therefore, developing selective catalysts for the direct production of targeted products through the FT process has attracted considerable attention from scientists.

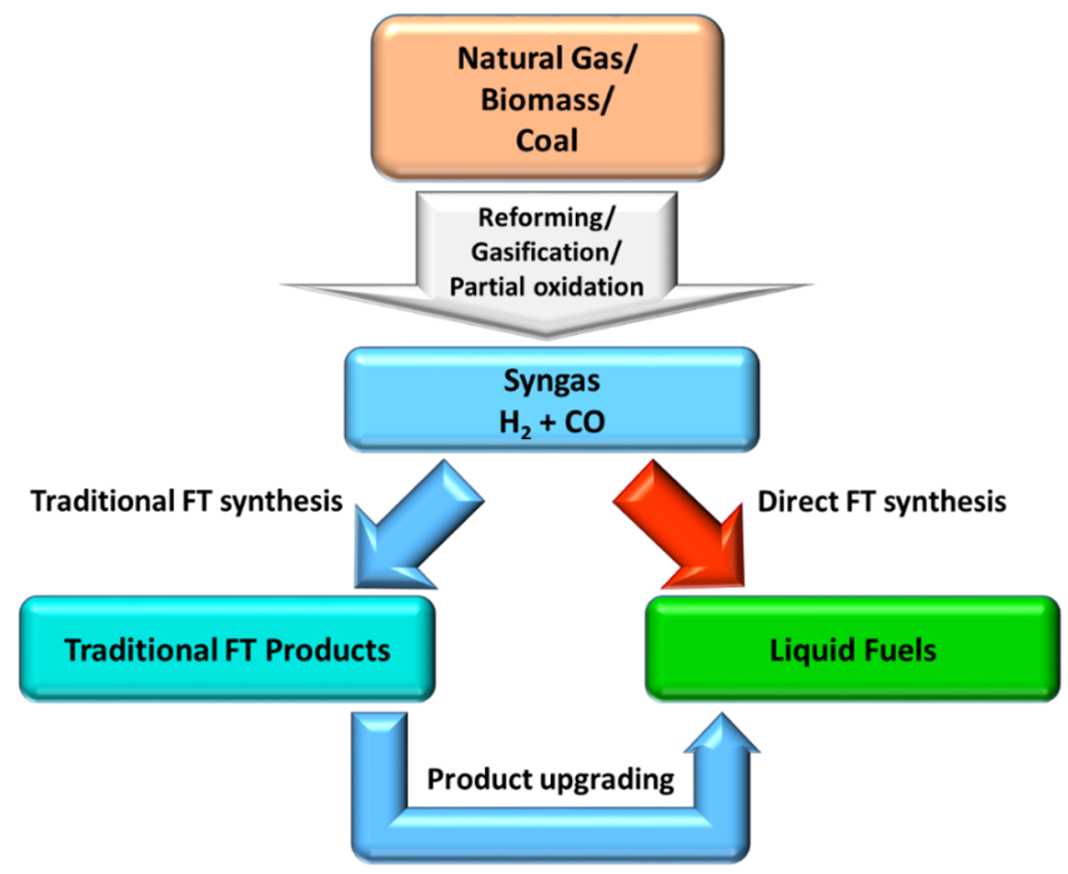

Figure 1. Transformation of carbonaceous resources (natural gas, biomass, and coal) into liquid fuels.

Cobalt-based catalysts with high selectivities to long-chain hydrocarbons, including diesel fuel and wax, are used more often than iron-based catalysts, which are suitable for gasoline production. Promoters can promote the reduction of cobalt oxide to its active metal phase and improve the catalyst's lifetime and mechanical stability by inhibiting carbon deposition on active $\mathrm{Co}^{0}$ and decreasing Co sintering [14]. The $25 \% \mathrm{Co} / \mathrm{Al}_{2} \mathrm{O}_{3}$ catalysts promoted by $\mathrm{Pt}$ have been used as an active catalyst for the production of aviation fuel in a continuous stirred tank reactor (CSTR) at $1.8 \mathrm{MPa}$ and $220{ }^{\circ} \mathrm{C}$ [15], and a CO conversion rate of approximately $30 \%$ and selectivity of $28 \%, 17 \%$, and $40 \%$ to $C_{5}-C_{11}, C_{12}-C_{18}$, and $\mathrm{C}_{19+}$, respectively, was observed. In another study, a $\mathrm{Co} / \mathrm{ZrO}_{2}-\mathrm{SiO}_{2}$ catalyst prepared through the incipient wetness impregnation method and its catalytic performance in the direct synthesis of jet fuel from syngas in a slurry phase reactor was investigated by Li et al. [8]. A $C_{8}-C_{16}$ selectivity of $29 \%$ was obtained at $1 \mathrm{MPa}$ and $240{ }^{\circ} \mathrm{C}$. However, the addition of a co-fed additive of syngas containing 1-decene and 1-tetradecene (1:1) resulted in a significant increase in selectivity. The addition of $\mathrm{Mn}$ to $\mathrm{Co} / \mathrm{TiO}_{2}$ catalysts increases $\mathrm{C}_{5+}$ selectivity (from $30.9 \%$ to $43.5 \%$ ) and decreases methane selectivity (from $32.7 \%$ to $22.3 \%$ ) [16]. Co-Mn interactions in catalysts prepared through homogeneous deposition precipitation (HDP) decrease the Co reducibility. The decrease in reducibility did not affect catalyst activity; rather, it improved selectivity to higher hydrocarbons $\left(\mathrm{C}_{5+}\right)$. The addition of $\mathrm{Mn}$ to $\mathrm{Co}$ catalysts prepared through an impregnation method did not cause changes in reduction temperature, probably because of the absence of interactions between $\mathrm{Mn}$ and Co in these catalysts [16].

Hydrotalcite-like compounds (HTCs) comprise atomically dispersed mixed metals and are excellent precursors and/or catalyst supports [17-19]. HTCs are brucite-like layer materials with 
a general formula of $\left(\mathrm{M}_{1-x}^{2+} \mathrm{M}_{x}^{3+}(\mathrm{OH})_{2}\right)^{x+}\left(A_{x / n}^{n-}\right)^{x-} \cdot m \mathrm{H}_{2} \mathrm{O}$, where partial metal cation $\mathrm{M}^{2+} / \mathrm{M}^{3+}$ replacement occurs and the excess of positive charge is counterbalanced by anions $\mathrm{A}^{\mathrm{n}-}$ (such as $\mathrm{CO}_{3}^{2-}, \mathrm{SO}_{4}^{2-}, \mathrm{NO}_{3}^{-}$, or other organic anions such as terephthalate) existing in interlayers, together with water molecules, and $x=\mathrm{M}^{3+} /\left(\mathrm{M}^{2+}+\mathrm{M}^{3+}\right)$, which generally ranges from 0.2 to 0.33 , is the surface charge determined by the ratio of two metal cations; it can be changed for different applications [20,21]. HTCs can be synthesized as catalyst precursors with divalent metal cations $\left(\mathrm{M}^{2+}\right)\left(\right.$ e.g., $\mathrm{Mg}^{2+}, \mathrm{Ni}^{2+}$, $\mathrm{Co}^{2+}, \mathrm{Cu}^{2+}$, or $\mathrm{Zn}^{2+}$ ) and trivalent cations $\left(\mathrm{M}^{3+}\right)\left(\right.$ e.g., $\left.\mathrm{Mn}^{3+}, \mathrm{Al}^{3+}, \mathrm{Fe}^{3+}, \mathrm{Cr}^{3+}, \mathrm{Rh}^{3+}, \mathrm{Ru}^{3+}, \mathrm{Ga}^{3+} \mathrm{Or} \mathrm{In}^{3+}\right)$. The calcination of HTCs leads to their transformation into well-dispersed mixed metal oxides (MMOs) with high surface areas, numerous Lewis base sites, and good thermal stability against sintering. These features are highly suitable for catalysis applications. The formation of $\mathrm{O}^{2}-\mathrm{M}^{\mathrm{n}+}$ acid-base pairs is associated with the types of acidic-basic sites. The Lewis acidity is associated with the presence of low-coordination $\mathrm{O}^{2}$ species that closely interact with $\mathrm{M}^{3+}$ cations, and Lewis basicity is due to $\mathrm{M}^{2+}$ cations $[22,23]$. The nature and strength of the acidic-basic sites of hydrotalcite-like compounds can be adjusted by adjusting the following parameters: (1) the nature of substituting cations in hydrotalcite structures; (2) characteristic $\mathrm{M}^{2+} / \mathrm{M}^{3+}$ molar ratio; (3) nature of anions presented in interlayer regions; (4) thermal activation of layered materials; for example, a higher calcination temperature is favored for the creation of Lewis basic sites) [22,23].

The reduction of HTCs can be eminently suitable for the formation of highly dispersed and well-supported metallic particles [17-21,24-26]. Hydrotalcite-derived mixed oxides have been used as a catalyst in different catalytic reactions, such as steam reforming of ethanol $[20,27,28]$, $\mathrm{CO}_{2}$ hydrogenation to methanol [29,30], $\mathrm{CO}_{2}$ reforming of methane for syngas production [31-33], formation of alcohols from syngas [19,34,35], and hydrocarbon production through FT reaction [36]. In the present study, CoMn catalysts derived from hydrotalcite-like precursors, with a Co/Mn molar ratio of 2, were synthesized using different preparation methods, and their catalytic activities in the FT reaction were evaluated. The physicochemical properties of the catalysts were characterized through thermogravimetric analysis (TG), inductively coupled plasma (ICP), scanning electron microscopy (SEM), hydrogen temperature-programmed reduction $\left(\mathrm{H}_{2}-\mathrm{TPR}\right)$, ammonia temperature-programmed desorption $\left(\mathrm{NH}_{3}-\mathrm{TPD}\right)$, and $\mathrm{X}$-ray diffraction $(\mathrm{XRD})$, and the effects of different preparation methods on the structures and catalytic performance of the catalysts were investigated.

\section{Results and Discussion}

\subsection{Characterization of Catalysts}

The inductively coupled plasma-optical emission spectrometry (ICP-OES) analysis was performed to determine the chemical composition of the prepared catalysts, and the results are listed in Table 1. The $\mathrm{Co} / \mathrm{Mn}$ molar ratios calculated from the ICP analysis are close to the theoretical value $(\mathrm{Co} / \mathrm{Mn}=2)$, indicating the complete precipitation of metal ions. The thermogravimetric analysis (TGA) and derivative thermogravimetric (DTG) curves for the CoMn catalysts derived from hydrotalcite-like precursors (CoMn-HTC catalysts) (Figure 2) exhibited several phases of weight loss because of the thermal decomposition of catalysts, and the same behavior was observed in the DTG curves. The peaks at $100-260{ }^{\circ} \mathrm{C}$ were attributed to the evaporation of physically adsorbed water and interpolated water molecules associated with the dried samples. This result is in good agreement with the mass spectroscopy results, showing that water was released at this temperature range, and weight loss mainly occurred at this range. The weak peak observed at higher temperatures was caused by the elimination of hydroxyl and carbonate anions from the interlayer space, along with interlayer water. Weight loss in the catalysts precipitated with $\mathrm{KOH}$ (group 2) was lower than that in the catalysts prepared using a mixture of $\mathrm{KOH}+\mathrm{K}_{2} \mathrm{CO}_{3}$ as a precipitating agent. Compared with the other catalysts in each group, the catalysts prepared with the addition of $\mathrm{H}_{2} \mathrm{O}_{2}$ had a lower weight loss than the other catalysts. The peaks for released $\mathrm{CO}_{2}$ were observed at around $280^{\circ} \mathrm{C}$ and $240^{\circ} \mathrm{C}$ for catalysts I and II, and no apparent peaks were observed for the other catalysts. The amount of released $\mathrm{CO}_{2}$ is much 
lower than that of released water. The low amount of released $\mathrm{CO}_{2}$ may be due to the adsorption of $\mathrm{CO}_{2}$ from air during the measurement.

Table 1. Inductively coupled plasma (ICP) analysis of the CoMn-HTC catalysts.

\begin{tabular}{cccccc}
\hline \multirow{2}{*}{ Samples } & \multicolumn{2}{c}{ Concentration (wt. $\%)$} & \multicolumn{2}{c}{ Concentration (mol\%) } & Molar Ratio \\
\cline { 2 - 6 } & $\mathbf{C o}$ & $\mathbf{M n}$ & $\mathbf{C o}$ & $\mathbf{M n}$ & $\mathbf{C o} / \mathbf{M n}$ \\
\hline CoMn-HTC-I. & 41.3 & 14.7 & 0.70 & 0.27 & 2.62 \\
\hline CoMn-HTC-II. & 41.0 & 15.2 & 0.70 & 0.28 & 2.51 \\
\hline CoMn-HTC-III. & 42.3 & 19.5 & 0.72 & 0.35 & 2.02 \\
\hline CoMn-HTC-IV. & 44.1 & 18.6 & 0.75 & 0.34 & 2.21 \\
\hline CoMn-HTC-V. & 41.2 & 16.6 & 0.70 & 0.30 & 2.31 \\
\hline CoMn-HTC-VI. & 43.3 & 18.6 & 0.73 & 0.34 & 2.17 \\
\hline
\end{tabular}
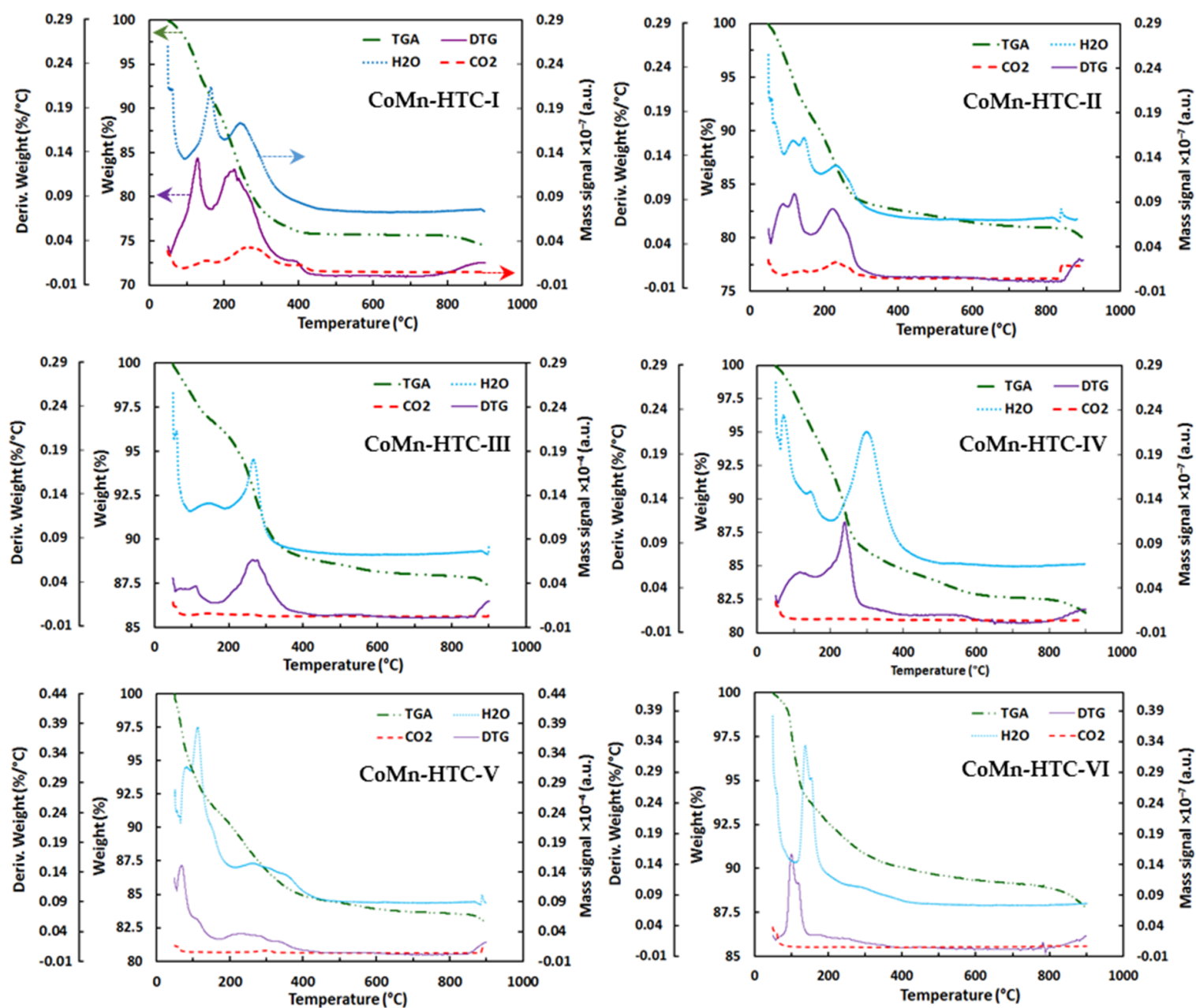

Figure 2. Thermogravimetric analysis and mass spectrometry detector (TGA-MS) analysis of the CoMn-HTC catalysts.

The reducibility of CoMn-HTC catalysts was analyzed through hydrogen temperatureprogrammed reduction $\left(\mathrm{H}_{2}-\mathrm{TPR}\right)$ analysis (Figure 3). The TPR profiles revealed two regions of low-temperature range at $180-450{ }^{\circ} \mathrm{C}$ and high-temperature range at $450-730{ }^{\circ} \mathrm{C}$. The first weak peak in the range of $199-237^{\circ} \mathrm{C}$ was ascribed to the partial reduction of easily reducible species of CoMn composite oxide:

$$
\mathrm{Mn}_{\mathrm{x}} \mathrm{Co}_{\mathrm{y}} \mathrm{O}_{\mathrm{z}}(\mathrm{s})+\mathrm{H}_{2}(\mathrm{~g}) \rightarrow \mathrm{Mn}_{3} \mathrm{O}_{4}-\mathrm{Co}_{3} \mathrm{O}_{4}(\mathrm{~s})+\mathrm{H}_{2} \mathrm{O}(\mathrm{g})
$$




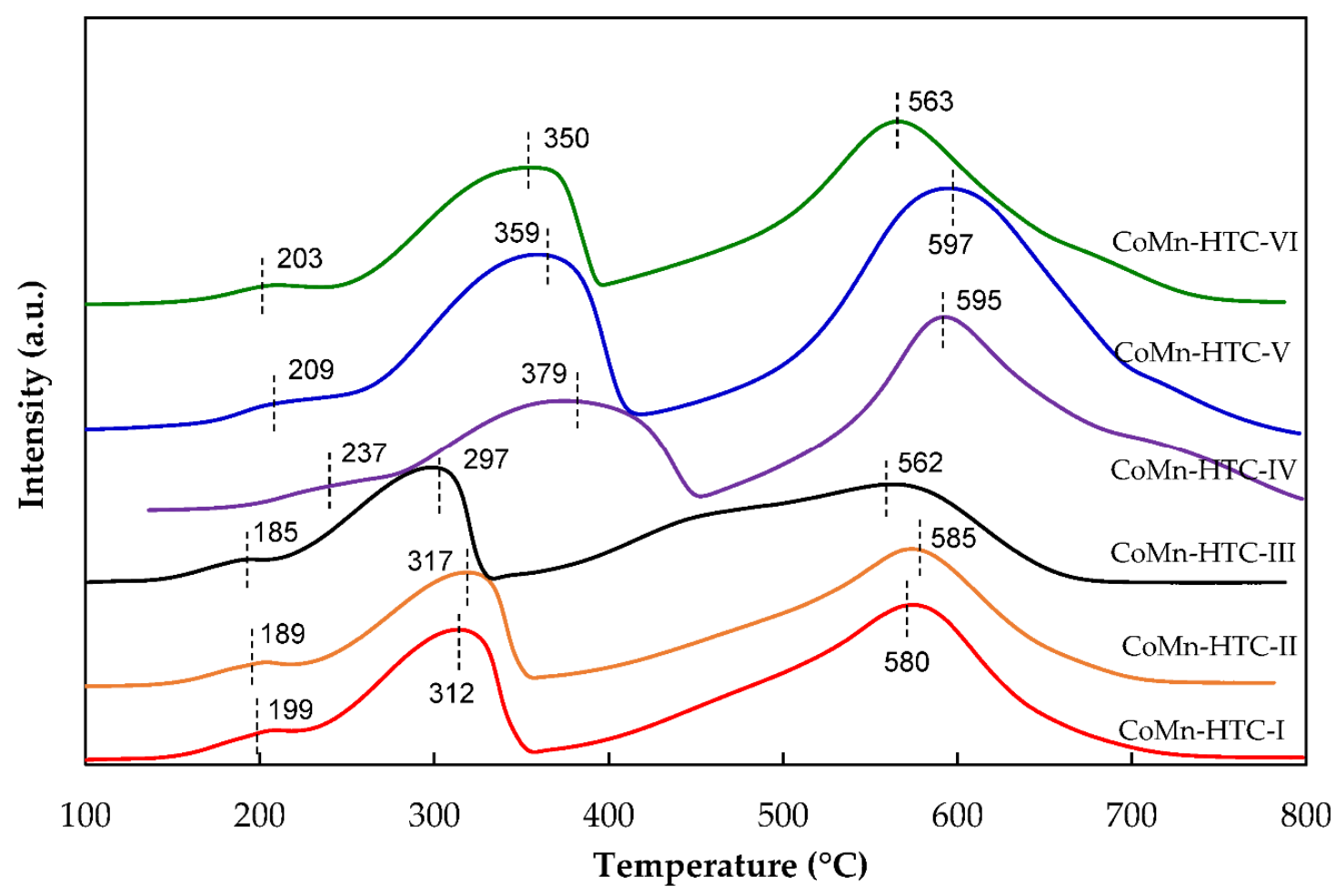

Figure 3. Hydrogen temperature-programmed reduction ( $\left.\mathrm{H}_{2}-\mathrm{TPR}\right)$ profiles of the CoMn-HTC catalysts.

The second peak at $300-380{ }^{\circ} \mathrm{C}$ was attributed to the further reduction of $\mathrm{Mn}_{3} \mathrm{O}_{4}$ to $\mathrm{MnO}$ and $\mathrm{Co}_{3} \mathrm{O}_{4}$ to $\mathrm{CoO}$ :

$$
\mathrm{Mn}_{3} \mathrm{O}_{4}-\mathrm{Co}_{3} \mathrm{O}_{4}(\mathrm{~s})+\mathrm{H}_{2}(\mathrm{~g}) \rightarrow \mathrm{MnO}-\mathrm{CoO}(\mathrm{s})+\mathrm{H}_{2} \mathrm{O}(\mathrm{g})
$$
to $\mathrm{MnO}$ :

The peaks at high temperature $\left(>450^{\circ} \mathrm{C}\right)$ were ascribed to the reduction of $\mathrm{CoO}$ to $\mathrm{Co}$ and $\mathrm{Mn}_{3} \mathrm{O}_{4}$

$$
\mathrm{MnO}-\mathrm{CoO}(\mathrm{s})+\mathrm{H}_{2}(\mathrm{~g}) \rightarrow \mathrm{MnO}(\mathrm{s})+\mathrm{Co}(\mathrm{s})+\mathrm{H}_{2} \mathrm{O}(\mathrm{g})
$$

Compared with the TPR peaks of the catalysts prepared by $\mathrm{KOH}$ as the precipitating agent, the TPR peaks for the catalysts prepared by the mixture of $\mathrm{KOH}+\mathrm{K}_{2} \mathrm{CO}_{3}$ as the precipitating agent shifted to lower temperatures. Precipitation in the presence of air did not cause a considerable change in catalyst II compared with catalyst I, while the peaks of catalysts V shifted to lower temperatures than those of catalyst IV. In CoMn-HTC III (from group 1) and CoMn-HTC VI (from group 2) catalysts (catalysts prepared with the addition of $\mathrm{H}_{2} \mathrm{O}_{2}$ ), all peaks shifted to lower temperatures compared with the catalysts of each group prepared without the addition of air or $\mathrm{H}_{2} \mathrm{O}_{2}$. The different TPR profiles of CoMn-HTC catalysts could be due to the different $\mathrm{Mn}$ and Co species interactions, which are related to the preparation methods. The CoMn-HTC III catalyst had the lowest reduction temperatures. Thus, the preparation of catalysts precipitated by the mixture of $\mathrm{KOH}+\mathrm{K}_{2} \mathrm{CO}_{3}$ in the presence of $\mathrm{H}_{2} \mathrm{O}_{2}$ enhanced the catalyst reducibility. Jung et al. [37] studied the effect of precipitants on nickel-based catalysts prepared through the co-precipitation method, and it was found that the catalysts prepared with $\mathrm{K}_{2} \mathrm{CO}_{3}$ as the precipitating agent had lower reduction temperatures and a higher hydrogen uptake than those precipitated with $\mathrm{KOH}$. The catalyst prepared with $\mathrm{K}_{2} \mathrm{CO}_{3}$ also exhibited high pore volume and good catalytic activity for methane steam reforming [37].

The acidic properties of the prepared catalysts were determined through ammonia temperature-programmed desorption $\left(\mathrm{NH}_{3}-\mathrm{TPD}\right.$ ) analysis (Figure 4). The peaks at low temperatures, below $200{ }^{\circ} \mathrm{C}$, were attributed to weak acid sites or physically adsorbed ammonia, and the peaks at higher temperatures in the range of $200-400{ }^{\circ} \mathrm{C}$, were associated with the medium interaction between Brønsted acid sites and $\mathrm{NH}_{3}$. The peaks at temperatures above $400{ }^{\circ} \mathrm{C}$ belong to strong acid 
sites [38-40]. Table 2 shows the concentration of both weak and medium acid sites $\left(\mathrm{mmol} \mathrm{NH}_{3} / \mathrm{g}_{\mathrm{cat}}\right)$ of the catalysts. The acid sites (weak and medium acid sites) decreased, and the peaks shifted to higher temperatures in the catalysts prepared with $\mathrm{KOH}$. Medium acid sites increased in both catalyst groups (precipitated by a mixture of $\mathrm{KOH}+\mathrm{K}_{2} \mathrm{CO}_{3}$, and $\mathrm{KOH}$ ) when they were precipitated by the addition of $\mathrm{H}_{2} \mathrm{O}_{2}$ to enhance the oxidation of metals.

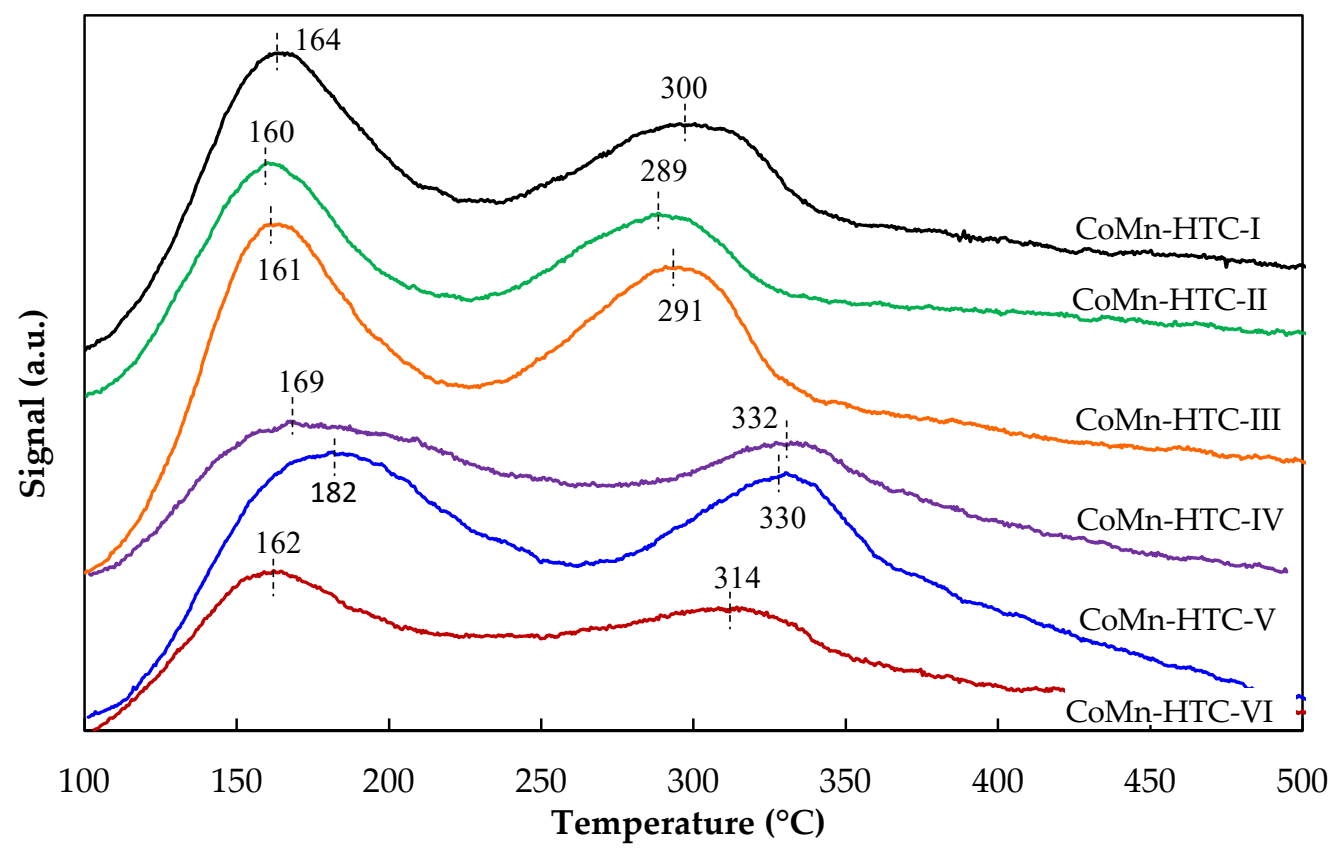

Figure 4. Ammonia temperature-programmed desorption $\left(\mathrm{NH}_{3}-\mathrm{TPD}\right)$ profiles of the CoMn-HTC catalysts.

Table 2. Surface acidity of CoMn catalysts measured by ammonia temperature-programmed desorption $\left(\mathrm{NH}_{3}-\mathrm{TPD}\right)$.

\begin{tabular}{cccc}
\hline \multirow{2}{*}{ Catalyst } & \multicolumn{3}{c}{ Acidic Site $\left(\mathbf{m m o l ~} \mathbf{N H}_{3} / \mathbf{g}\right)$} \\
\cline { 2 - 4 } & First Peak & Second Peak & Total \\
\hline CoMn-HTC-I & 0.172 & 0.276 & 0.448 \\
\hline CoMn-HTC-II & 0.147 & 0.201 & 0.348 \\
\hline CoMn-HTC-III & 0.184 & 0.353 & 0.537 \\
\hline Co-Mn-HTC-IV & 0.212 & 0.104 & 0.316 \\
\hline CoMn-HTC-V & 0.208 & 0.196 & 0.404 \\
\hline CoMn-HTC-VI & 0.073 & 0.151 & 0.224 \\
\hline
\end{tabular}

The higher number of acid sites could be attributed to the porous structure of the catalyst. The surface acidity of porous $\mathrm{Mn}_{2} \mathrm{Co}_{1} \mathrm{O}_{x}$ catalysts prepared by the combustion (CB) and co-precipitation (CP) methods was studied by Qiao et al. [41]. They found that the ammonia desorption peaks shifted to a lower temperature region for the catalyst prepared by the co-precipitation method. The desorption of $\mathrm{NH}_{4}^{+}$ions bonded to Brønsted acid sites are easier at lower temperatures. For the catalyst prepared by the combustion method, with larger specific surface area and porous structures than those prepared by the co-precipitation method, the peaks shifted to slightly higher temperatures, indicating the presence of abundant Lewis acid sites; the stronger acid strength could be due to the stronger interaction between the cobalt oxide and manganese oxide species [41]. Since the acid sites enhance the cracking and isomerization of heavier hydrocarbons [12], the catalysts with higher acid sites are expected to have better performance for the production of lighter hydrocarbons. Liu et al. [42] reported that the 
$\mathrm{H}_{2} \mathrm{O}_{2}$-modified catalysts have a larger number of surface acid sites, especially Brønsted acid sites. They reported that the $\mathrm{NH}_{3}$-TPD peaks at low temperatures $\left(<250{ }^{\circ} \mathrm{C}\right)$ are due to the desorption of physisorbed ammonia and partial ionic $\mathrm{NH}_{4}^{+}$bound to weak Brønsted acid sites, and the peaks at higher temperatures $\left(>250{ }^{\circ} \mathrm{C}\right.$ ) belong to the Lewis acid sites and ionic $\mathrm{NH}_{4}^{+}$bound to Brønsted acid sites. Brønsted acid sites are ascribed to surface protons, whereas Lewis acid sites, which are stronger than Brønsted sites, are attributed to the $\mathrm{Co}-\mathrm{O}-\mathrm{Mn}$ species located within a $\mathrm{CoO}$ structure and containing $\mathrm{Mn}^{3+}$ cations mainly in octahedral sites.

The X-ray diffraction (XRD) patterns of the prepared catalysts are shown in Figure 5. The XRD patterns of dried catalysts (Figure 5a) showed that the CoMn-HTC catalysts had crystallized hydrotalcite structure forms, with characteristic peaks at $11.9^{\circ}, 23.5^{\circ}, 34.3^{\circ}, 39^{\circ}, 47.5^{\circ}, 60.8^{\circ}$, and $62.9^{\circ}$, which correspond to the (0 03 ), (0 06 6), (0 0 9), (0 1 5), (0 1 8), (1 110$)$, and (1 13 3) planes (JCPDS \#70-2151) [43-45].
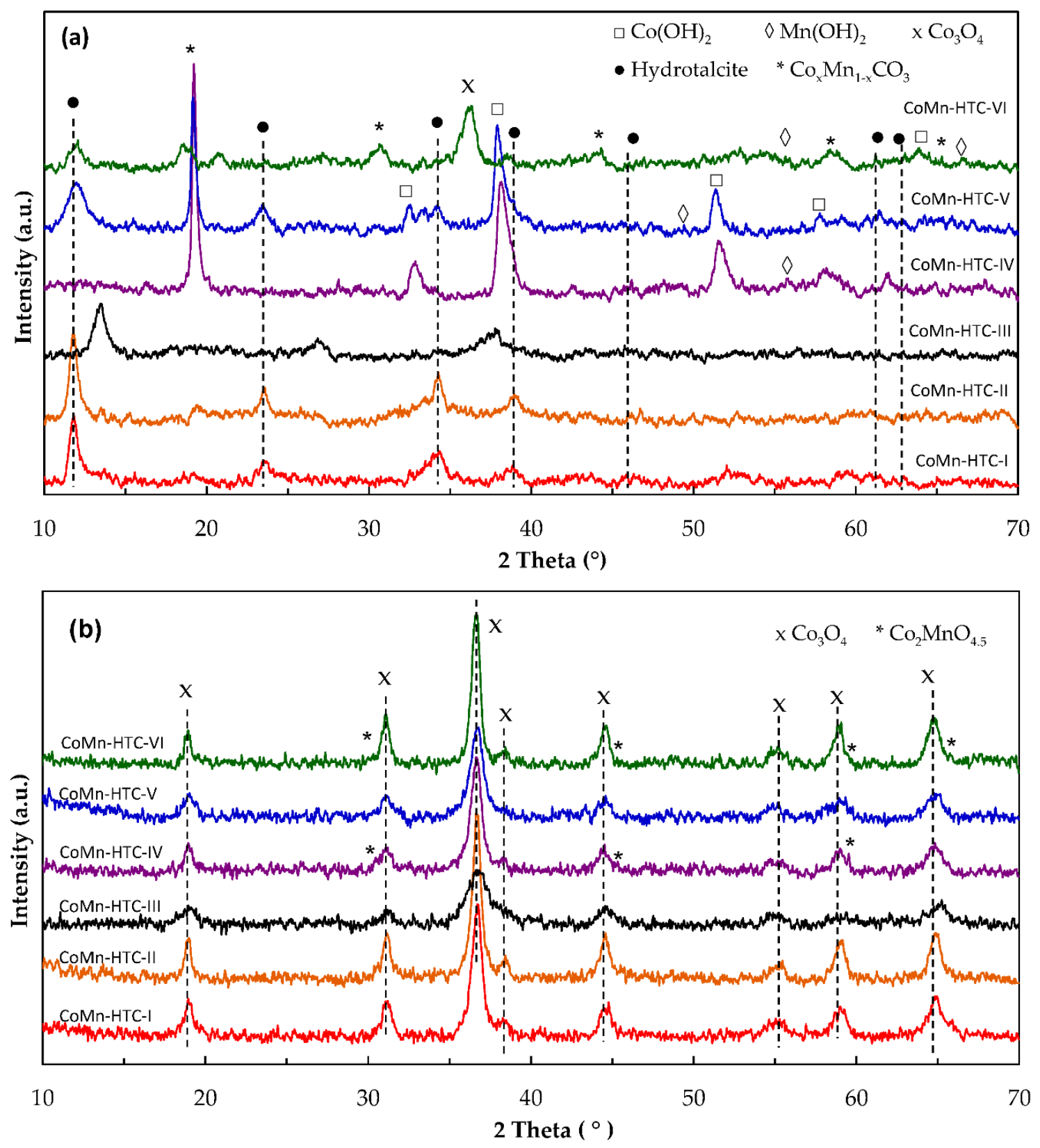

Figure 5. X-ray diffraction (XRD) patterns of the (a) dried and (b) calcined CoMn-HTC catalysts. 
The CoMn-HTC-IV, CoMn-HTC-V, and CoMn-HTC-VI catalysts had no clear layered structure and did not show apparent peaks belonging to the hydrotalcite structure. Most peaks were attributed to CoMn composite carbonate $\left(\mathrm{Co}_{x} \mathrm{Mn}_{1-x} \mathrm{CO}_{3}\right)$ in the catalysts prepared with $\mathrm{KOH}$. The peaks of the hydrotalcite structure in the CoMn-HTC-III catalyst shifted to the right (mainly on the characteristic basal plane 003 ), and this can be attributed to the presence of anions in the interlayer regions. The difference in anions (carbonate or hydroxyl) occurred during the catalyst synthesis process, and $\mathrm{H}_{2} \mathrm{O}_{2}$ addition or air bubbling during the precipitation process affected the competition among anions occupying the interlayer region. The small peaks at $60.8^{\circ}$ and $62.9^{\circ}$ were attributed to the interlayers of carbonate and nitrate anions [46]. The presence of the peaks belonging to $\mathrm{Co}(\mathrm{OH})_{2}$ and $\mathrm{Mn}(\mathrm{OH})_{2}$ could be due to incomplete moisture removal during the drying process. After calcination at $300{ }^{\circ} \mathrm{C}$ in air, no peaks associated with the hydrotalcite phase were observed in the XRD patterns (Figure 5b), indicating the destruction of the layered structure and the transformation of the hydrotalcite phase into $\mathrm{Co}_{3} \mathrm{O}_{4}$ (JCPDS \#42-1467) [21,46-48] in all prepared catalysts. The crystalline phase of the catalysts prepared by $\mathrm{KOH}$ contained some spinel $\mathrm{Co}_{2} \mathrm{MnO}_{4.5}$, with higher reduction temperatures and lower catalytic activities.

The scanning electron microscope (SEM) images of the CoMn-HTC catalysts after drying are shown in Figure 6. The effects of catalyst preparation methods on the catalyst morphology were investigated. The prepared CoMn hydrotalcites were formed by the accumulation of aggregated nanoparticles. The CoMn-HTC-III catalyst showed a more obvious plate-like layered structure than the other catalysts. This result showed that using a mixture of $\mathrm{KOH}+\mathrm{K}_{2} \mathrm{CO}_{3}$ and the addition of $\mathrm{H}_{2} \mathrm{O}_{2}$ have a positive effect on the preparation of hydrotalcite structured catalysts. In addition, the CoMn-HTC-III catalyst had the lowest reduction temperature possible because of its better layered structure. The distributions of metals were examined by performing the energy-dispersive X-ray spectroscopy (EDX) mapping of the catalysts (Figure 7). Mn and Co were homogeneously distributed over the entirety of the catalyst particles. The dispersion of cobalt and manganese particles could be promoted by the addition of hydrogen peroxide during the catalyst preparation and enhances crystal grain growth. Cui et al. [49] and Liu et al. [42] also reported that the addition of $\mathrm{H}_{2} \mathrm{O}_{2}$ could promote the dispersion of metal particles and improve the crystal grain growth, and this consequently resulted in the formation of mixed oxides with good thermal stability. 

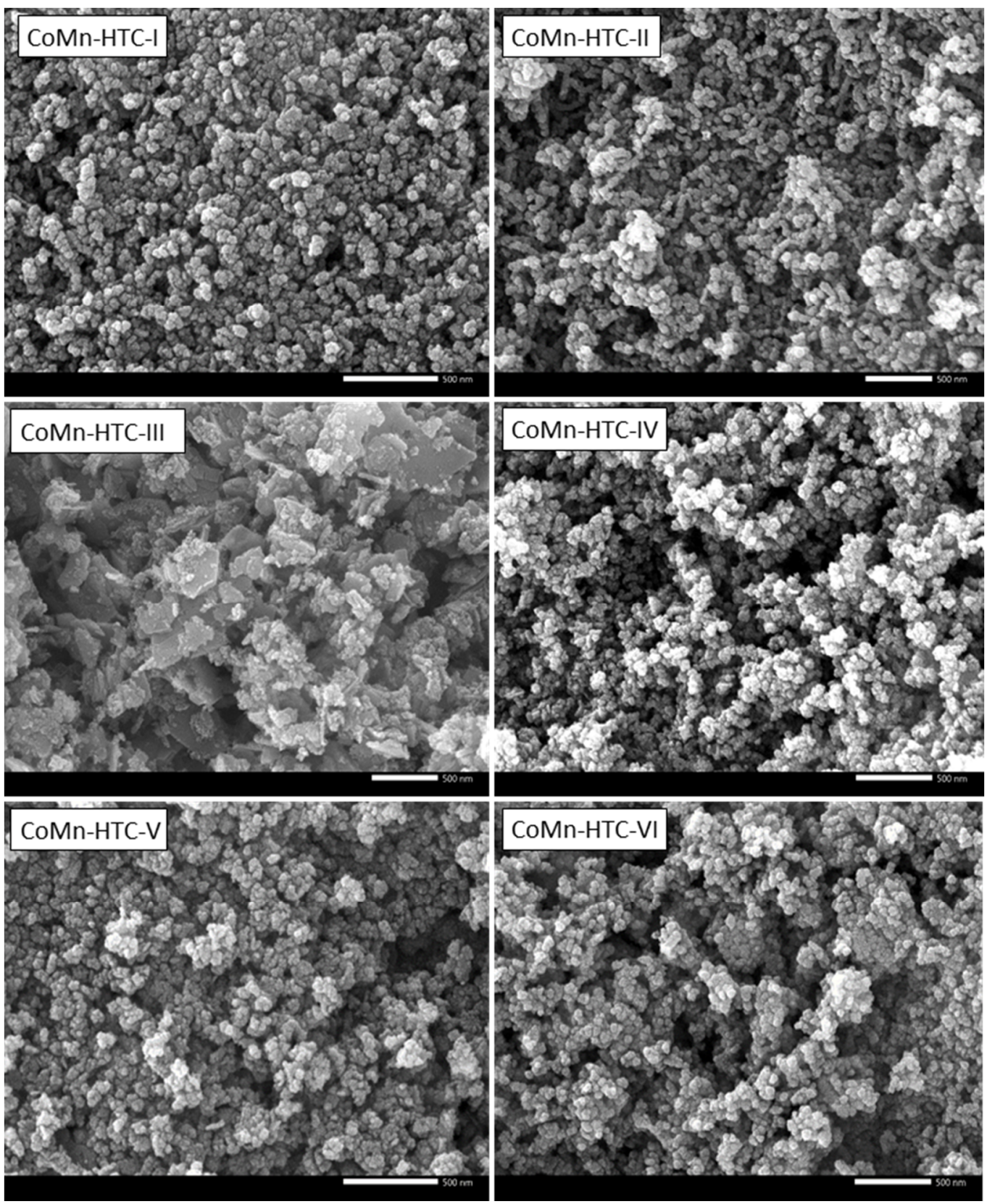

Figure 6. Scanning electron microscope (SEM) images of the CoMn-HTC catalysts. 


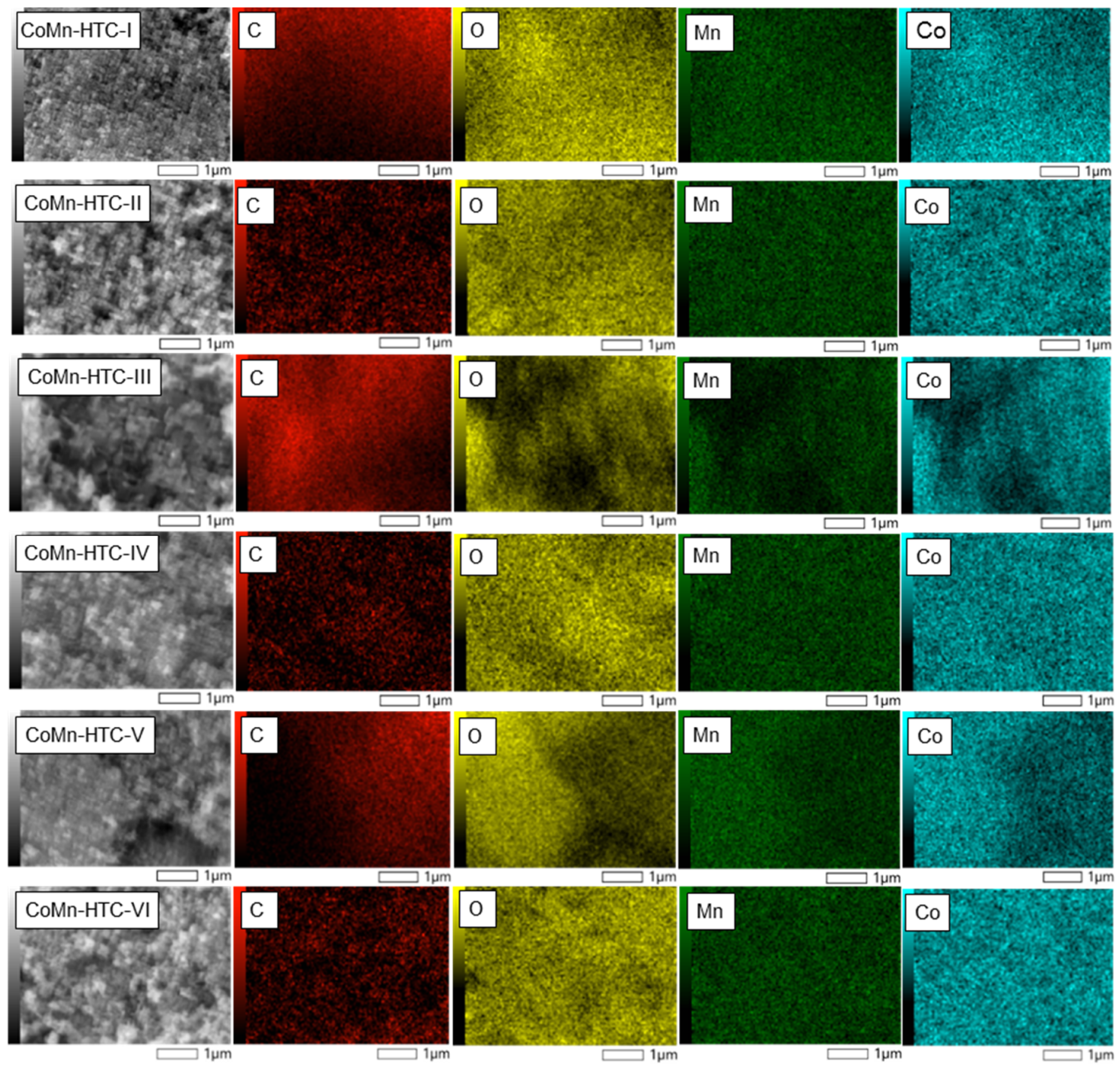

Figure 7. Energy-dispersive X-ray spectroscopy (EDX) mapping of the CoMn-HTC catalysts.

\subsection{Catalytic Evaluation}

Generally, FT synthesis products consist of light gaseous hydrocarbons $\left(C_{1}-C_{4}\right)$, liquid fuels $\left(\mathrm{C}_{5}-\mathrm{C}_{22}\right)$, and waxes $\left(\mathrm{C}_{23+}\right)$. The catalytic performance of calcined CoMn-HTC catalysts in FT reaction at $\mathrm{H}_{2} / \mathrm{CO}=2$, with a reaction temperature of $240{ }^{\circ} \mathrm{C}$, pressure of $7 \mathrm{MPa}$, and reaction time of $6 \mathrm{~h}$ are shown in Figure 8. The product distribution over two different groups of catalysts, (I, II, III) and (IV, V, VI), were different. The catalysts I, II, and III, which were prepared by a mixture of $\mathrm{KOH}+\mathrm{K}_{2} \mathrm{CO}_{3}$ as the precipitating agent, showed a higher potential in the production of liquid fuels including gasoline $\left(C_{5}-C_{10}\right)$ (Figure $\left.8 \mathrm{a}\right)$ and jet fuel range hydrocarbons $\left(C_{8}-C_{16}\right)$ (Figure $\left.8 b\right)$, whereas the other catalysts $(\mathrm{IV}, \mathrm{V}, \mathrm{VI})$ showed a higher potential in the formation of heavier hydrocarbons. 

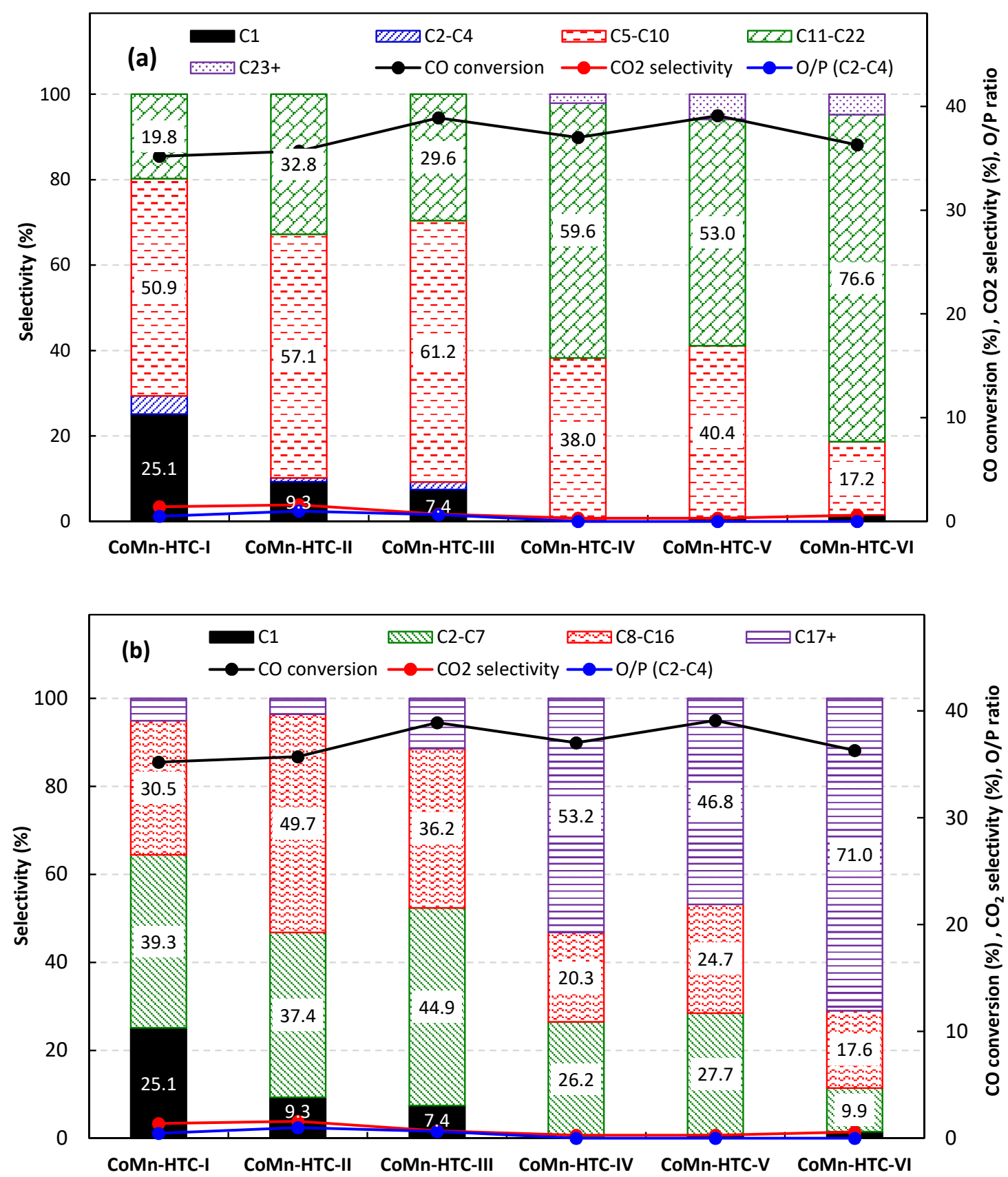

Figure 8. Product distribution in the Fischer-Tropsch (FT) reaction over CoMn-HTC catalysts: (a) gasoline range hydrocarbons $\left(C_{5}-C_{10}\right)$, and (b) jet fuel range hydrocarbons $\left(C_{8}-C_{16}\right)$. Reaction conditions: $\mathrm{H}_{2} / \mathrm{CO}=2,240{ }^{\circ} \mathrm{C}, 7 \mathrm{MPa}, 6 \mathrm{~h}$.

The CoMn-HTC-I catalyst exhibited $48.6 \%$ selectivity to $\mathrm{C}_{5}-\mathrm{C}_{10}$ and $30.5 \%$ to jet fuel. The CoMn-HTC-III catalyst had the highest selectivity of $61.2 \%$ to gasoline range hydrocarbons with the methane selectivity of $7.4 \%$. The simultaneous addition of $\mathrm{H}_{2} \mathrm{O}_{2}$ during the precipitation process also leads to an increase in the CO conversion, from $35.2 \%$ to $38.9 \%$. The CoMn-HTC-II catalyst had the highest selectivity $(49.7 \%)$ for jet fuel range hydrocarbons. The product distributions on catalysts IV, V, and VI revealed that the methane selectivity decreased to less than $1 \%$, and selectivities to $C_{5}-C_{10}$ and $C_{8}-C_{16}$ also decreased to $17-40 \%$ and $17-25 \%$, respectively. The selectivity to $C_{17+}$ in these catalysts was considerably higher than those in catalysts of group I, which were prepared by a mixture of $\mathrm{KOH}+\mathrm{K}_{2} \mathrm{CO}_{3}$ as the precipitating agent. Very small amounts of olefins were detected over the CoMn-HTC catalysts at the given reaction conditions. The CO conversion did not change 
considerably over different catalysts, and it was in the range of $35-39 \%$ for all catalysts. The $\mathrm{CO}_{2}$ formation rates in all catalysts were less than $2 \%$, implying that the CoMn-HTC catalysts had extremely poor activity for the water-gas shift reaction (WGS: $\mathrm{CO}+\mathrm{H}_{2} \mathrm{O} \rightarrow \mathrm{CO}_{2}+\mathrm{H}_{2}$ ).

The reduction temperature of easily reducible species of CoMn composite oxide decreased in both air-bubbled and $\mathrm{H}_{2} \mathrm{O}_{2}$ added catalysts, and this decrease resulted in a slight increase in catalytic activity because of the formation of additional $\mathrm{Mn}^{3+}$ and more CoMn species, which are easy to reduce. In addition to the reducibility of the catalyst, accessible catalyst acid sites can greatly affect the product distribution. The in situ cracking of the FT products may have been affected by the surface acidity of the catalysts. In general, Brønsted acidity leads to the cracking/isomerization of FT waxes [12]. The integrated synthesis of gasoline, jet fuel, and diesel range hydrocarbons using cobalt catalysts supported on mesoporous Y-type zeolites were studied by Li et al. [12]; they found that the porosity and acidic properties of zeolites play an important role in product distribution, mainly affecting the chain growth and cracking of heavier hydrocarbons. The $\mathrm{NH}_{3}$-TPD analysis revealed that the CoMn-HTC-III catalyst had higher Brønsted acid sites, which promoted the cracking of heavy hydrocarbons and the formation of $\mathrm{C}_{5}-\mathrm{C}_{10}$ fraction. Catalysts I, II, and III, owing to the accessibility of their Brønsted acid sites and higher possibility for the cracking of heavy hydrocarbons, showed high selectivity to the gasoline range hydrocarbons $\left(C_{5}-C_{10}\right)$ and jet fuel range hydrocarbons $\left(C_{8}-C_{16}\right)$. However, excessive Brønsted acidity on the catalysts may have resulted in low catalyst stability and overcracking of heavy hydrocarbons and a subsequent increase in the fraction of lighter hydrocarbons and methane. Catalytic activity is strongly related to the types of precursor and precipitant agent. As it can be seen in Figure 8, a very small amount of olefinic products was produced during the reaction, the highest $\mathrm{O} / \mathrm{P}$ ratio of $\mathrm{C}_{2}-\mathrm{C}_{4}$ hydrocarbon range of 1 was observed for catalyst II, and the highest $\mathrm{O} / \mathrm{P}$ ratio in the whole range of produced hydrocarbon was less than 0.05 . Oxygenated products were not detected in the products of the reaction for all catalysts.

According to Cai et al. [50], the activity of the copper manganese oxides catalysts prepared using sodium carbonate $\left(\mathrm{Na}_{2} \mathrm{CO}_{3}\right)$ as the precipitating agent was higher than the catalyst precipitated by sodium hydroxide $(\mathrm{NaOH})$ for the $\mathrm{CO}$ oxidation reaction. The crystalline phase of catalysts prepared using strong electrolyte $\left(\mathrm{OH}^{-}\right)$was found to be mainly spinel $\mathrm{Cu}_{1.5} \mathrm{Mn}_{1.5} \mathrm{O}_{4}$; catalysts prepared using weak electrolyte $\left(\mathrm{CO}_{3}^{2-}\right)$ mainly consisted of $\mathrm{MnCO}_{3}, \mathrm{Mn}_{2} \mathrm{O}_{3}$, and $\mathrm{CuO}$. The catalytic activities of the multiphase catalysts (containing $\mathrm{CuO}$ and $\mathrm{Mn}_{2} \mathrm{O}_{3}$ ) were several times higher than those of single-phase oxides, especially at low temperature ranges [50].

It is worth mentioning that the available cobalt active sites of the catalyst are responsible for the chain growth, and the accessible acid sites are responsible for the cracking and isomerization. In this study, it was observed that the first group of catalysts (I, II, and III), with more available active sites at lower temperatures and more available acid sites (mainly medium strength acid sites), showed higher selectivity to $C_{5}-C_{10}$ and $C_{8}-C_{16}$ hydrocarbons than the second group of catalysts. Owing to their lower acidic properties and the inferior cracking rates of the heavy hydrocarbons, catalysts IV, $\mathrm{V}$, and VI revealed higher selectivity for the production of hydrocarbons heavier than the gasoline or jet fuel range of hydrocarbons, and they also showed a considerably lower selectivity to methane.

\section{Materials and Methods}

\subsection{Catalyst Preparation}

CoMn-HTC catalysts $(\mathrm{Co} / \mathrm{Mn}$ molar ration $=2)$ with layered structures were synthesized by the co-precipitation method. Solution A was prepared by mixing cobalt nitrate $\left(\mathrm{Co}\left(\mathrm{NO}_{3}\right)_{2} \cdot 6 \mathrm{H}_{2} \mathrm{O}\right)$, manganese nitrates $\left(\mathrm{Mn}\left(\mathrm{NO}_{3}\right)_{2} \cdot 4 \mathrm{H}_{2} \mathrm{O}\right)$, and ammonium fluoride $\left(\mathrm{NH}_{4} \mathrm{~F}\right)$ in a $2000 \mathrm{~mL}$ beaker at room temperature. The mixture was continuously stirred for $60 \mathrm{~min}$. Two different basic solutions (solution $\mathrm{B}$ ) containing (1) $\left(\mathrm{KOH}(2 \mathrm{~mol} / \mathrm{L})+\mathrm{K}_{2} \mathrm{CO}_{3}(0.2 \mathrm{~mol} / \mathrm{L})\right)$ and $(2)(\mathrm{KOH}(2 \mathrm{~mol} / \mathrm{L}))$, were used as precipitating agents. Solution $\mathrm{B}$ was added dropwise to solution $\mathrm{A}$ with vigorous stirring, at $\mathrm{pH}=9$ and room temperature. Details of the catalyst preparation conditions are provided in Table 3. 
Table 3. Catalyst preparation conditions.

\begin{tabular}{cc}
\hline \multicolumn{1}{c}{ Catalyst } & Precipitating Agent \\
\hline CoMn-HTC-I (Group 1) & $\mathrm{KOH}+\mathrm{K}_{2} \mathrm{CO}_{3}$ \\
\hline CoMn-HTC-II (Group 1) & $\mathrm{KOH}+\mathrm{K}_{2} \mathrm{CO}_{3}+$ air bubbling \\
\hline CoMn-HTC-III (Group 1) & $\mathrm{KOH}+\mathrm{K}_{2} \mathrm{CO}_{3}+\mathrm{H}_{2} \mathrm{O}_{2}$ \\
\hline CoMn-HTC-IV (Group 2) & $\mathrm{KOH}$ \\
\hline CoMn-HTC-V (Group 2) & $\mathrm{KOH}+$ air bubbling \\
\hline CoMn-HTC-VI (Group 2) & $\mathrm{KOH}+\mathrm{H}_{2} \mathrm{O}_{2}$ \\
\hline
\end{tabular}

Catalysts I, II, and III were precipitated as hydrotalcite precursors with a $\mathrm{KOH}+\mathrm{K}_{2} \mathrm{CO}_{3}$ solution, and catalysts IV, V, and VI were precipitated by $\mathrm{KOH}$. In catalysts II and V, air was bubbled through precipitation for the oxidation of $\mathrm{Mn}^{2+}$ to $\mathrm{Mn}^{3+}$. Catalysts III and VI were precipitated by the simultaneous addition of $100 \mathrm{~mL}$ of $\mathrm{H}_{2} \mathrm{O}_{2}$ (30 vol.\%). The resulting solution was aged for $24 \mathrm{~h}$ at room temperature. The solid product was filtered and washed with deionized water to a neutral $\mathrm{pH}$, then dried at room temperature. The dried products were then calcined at $300^{\circ} \mathrm{C}$ for $5 \mathrm{~h}$ in air $\left(3^{\circ} \mathrm{C} / \mathrm{min}\right)$. The obtained catalysts were denoted as CoMn-HTC I to VI.

\subsection{Catalyst Characterizations}

The bulk metal contents in the prepared catalysts were determined using inductively coupled plasma-optical emission spectrometry (ICP-OES; Agilent 725/Agilent Technologies Inc., Santa Clara, CA, USA). Before analysis, approximately $0.5 \mathrm{~g}$ of catalyst was dissolved in $10 \mathrm{~mL}$ aqueous solution of $\mathrm{H}_{2} \mathrm{SO}_{4}$ (1:1) and heated. Then, the solution was cooled down and diluted with demineralized water and heated to $100^{\circ} \mathrm{C}$ for $2 \mathrm{~min}$. The obtained solution was then used for ICP analysis.

Thermogravimetric analysis (TGA) was carried out using the TGA Discovery series (TA Instruments, Lukens Drive, NW, USA). Approximately $20 \mathrm{mg}$ of the catalyst was placed in an open aluminum crucible and heated from $50{ }^{\circ} \mathrm{C}$ to $900{ }^{\circ} \mathrm{C}$ at $10^{\circ} \mathrm{C} / \mathrm{min}$ in a nitrogen atmosphere (20 mL/min). The fragments were detected using an OmniStar GSD320 quadrupole mass detector (Pfeiffer Vacuum Austria GmbH, Vienna, Austria).

The surface morphology of the prepared catalysts was studied using a scanning electron microscope (SEM) (JEOL JSM-IT500HR; JEOL Ltd., Tokyo, Japan) accessorized with energy-dispersive X-ray spectroscopy (EDX) for elemental analysis and map analysis. Representative backscattered electron or secondary electron images of microstructures were taken in high vacuum mode, using an accelerating voltage of $15 \mathrm{kV}$.

The X-ray diffraction (XRD) patterns of the prepared catalysts were measured using a D8 Advance ECO (Bruker AXC GmbH, Karlsruhe, Germany) with CuK $\alpha$ radiation $(\lambda=1.5406 \AA$ ). The step time was $0.5 \mathrm{~s}$, and the step size was $0.02^{\circ}$ in a $2 \theta$ angle ranging from $10^{\circ}$ to $70^{\circ}$. The diffractograms were evaluated using the Diffrac.Eva software with the Powder Diffraction File database (PDF 4+ 2018, International Centre for Diffraction Data).

Hydrogen temperature-programmed reduction $\left(\mathrm{H}_{2}-\mathrm{TPR}\right)$ and ammonia temperature-programmed desorption $\left(\mathrm{NH}_{3}-\mathrm{TPD}\right.$ ) analysis were performed using an Autochem $2950 \mathrm{HP}$ (Micromeritics Instrument Corporation, Norcross, GA, USA). In $\mathrm{H}_{2}$-TPR analysis, $50 \mathrm{mg}$ of catalyst was placed in the quartz tube. The catalyst sample was pretreated under argon flow at $450{ }^{\circ} \mathrm{C}\left(10^{\circ} \mathrm{C} / \mathrm{min}\right)$ for $30 \mathrm{~min}$ to remove traces of water and impurities from the catalyst pores, and it was then cooled to $40^{\circ} \mathrm{C} . \mathrm{H}_{2}$-TPR was performed using $10 \% \mathrm{H}_{2} /$ Ar with a flow rate of $30 \mathrm{~mL} / \mathrm{min}$ and heating from $40^{\circ} \mathrm{C}$ to $800^{\circ} \mathrm{C}\left(10^{\circ} \mathrm{C} / \mathrm{min}\right)$. In $\mathrm{NH}_{3}$-TPD analysis, approximately $0.1 \mathrm{~g}$ of catalyst was pretreated with $\mathrm{He}(25 \mathrm{~mL} / \mathrm{min})$ at $450^{\circ} \mathrm{C}$ $\left(10^{\circ} \mathrm{C} / \mathrm{min}\right)$ for $1 \mathrm{~h}$. After cooling to $80^{\circ} \mathrm{C}$, ammonia adsorption was carried out, and the catalyst was saturated with $10 \% \mathrm{NH}_{3} / \mathrm{He}(25 \mathrm{~mL} / \mathrm{min})$ at $80{ }^{\circ} \mathrm{C}$ for $1 \mathrm{~h}$. The physically bound molecules of ammonia were removed by purging with $\mathrm{He}(25 \mathrm{~mL} / \mathrm{min})$ at $100^{\circ} \mathrm{C}$ for $1 \mathrm{~h}$. Finally, $\mathrm{NH}_{3}$ desorption 
was performed by increasing the temperature from $100{ }^{\circ} \mathrm{C}$ to $800^{\circ} \mathrm{C}$, at a heating rate of $10^{\circ} \mathrm{C} / \mathrm{min}$ under $\mathrm{He}$, with a flow rate of $25 \mathrm{~mL} / \mathrm{min}$. A thermal conductivity detector (TCD) was used to detect desorbed $\mathrm{NH}_{3}$ in the outlet gas.

\subsection{Catalytic Evaluation}

The FT test was carried out in a $1 \mathrm{~L}$ stainless steel autoclave batch reactor (Parr instruments). In a typical experiment, $500 \mathrm{mg}$ of catalyst and $50 \mathrm{~mL}$ of cyclohexane as a solvent were added to the reactor vessel. For the in-situ reduction of catalyst, the reactor was sealed and purged with $\mathrm{N}_{2}$ five times and with $\mathrm{H}_{2}$ three times. The reactor was then heated to $300{ }^{\circ} \mathrm{C}$ at a ramping rate of $3{ }^{\circ} \mathrm{C} / \mathrm{min}$, then pressurized with $\mathrm{H}_{2}$ to $5 \mathrm{MPa}$ for $5 \mathrm{~h}$. After reduction, the reactor system was cooled to room temperature and purged three times with premixed syngas $\left(\mathrm{H}_{2} / \mathrm{CO}=2\right)$. The reactor temperature was raised to $240{ }^{\circ} \mathrm{C}$ at a ramping rate of $3{ }^{\circ} \mathrm{C} / \mathrm{min}$, then pressurized to $7 \mathrm{MPa}$ to conduct the reaction in batch mode under a constant stirring speed of $800 \mathrm{rpm}$ to eliminate the diffusion control region. A constant temperature was maintained during the reaction for $6 \mathrm{~h}$. The conversion rate was measured according to the decrease in pressure during the reaction. After the reaction was terminated, the products were analyzed using different chromatographic procedures. The resultant gas sample was transferred to a gas bag and analyzed with a gas chromatograph, Agilent 7890A, with three parallel channels which collect data at the same time. The channels are equipped with two thermal conductivity detectors (TCD), $\mathrm{CO}, \mathrm{H}_{2}, \mathrm{~N}_{2}$, and $\mathrm{CO}_{2}$ gases, and a flame ionization detector (FID) for the detection of hydrocarbons. The liquid samples were analyzed, without prior preparation steps, on chromatograph Agilent 7890A with FID detector using non-polar column HP PONA.

\section{Conclusions}

The effects of catalyst preparation methods on the physicochemical properties of CoMn-HTC catalysts derived from hydrotalcite-like precursors were investigated. The characterization results showed that the catalysts precipitated with $\mathrm{KOH}$ as a strong electrolyte $\left(\mathrm{OH}^{-}\right)$had higher reduction temperatures and lower reducibility, reduced and readily reducible species, and less accessible acid sites on the surface than the catalysts prepared with the $\mathrm{KOH}+\mathrm{K}_{2} \mathrm{CO}_{3}$ mixture as precipitating agent and thus had better catalyst reducibility and more accessible medium and strong acid sites. The catalytic performance of the prepared CoMn catalysts was evaluated for FT synthesis at $240{ }^{\circ} \mathrm{C}$, $7 \mathrm{MPa}$, and $\mathrm{H}_{2} / \mathrm{CO}=2$ in a batch autoclave reactor. The highest selectivity $(61 \%)$ was obtained after using the catalyst prepared with $\mathrm{KOH}+\mathrm{K}_{2} \mathrm{CO}_{3}$ mixture and the addition of $\mathrm{H}_{2} \mathrm{O}_{2}$ (CoMn-HTC-III). The selectivity to gasoline range hydrocarbons decreased from $61 \%$ to $36 \%$ after the precipitating agent was changed from mixed solution to $\mathrm{KOH}$ only. The $\mathrm{CO}$ conversion did not greatly change by variations in catalyst preparation methods and remained in the range of 35-39\% in all catalysts. $\mathrm{CO}_{2}$ formation was less than $2 \%$ regardless of the catalyst used, indicating the extremely poor and negligible activity of the catalysts for the water-gas shift reaction.

Author Contributions: Conceptualization and experimental work designed and supported by Z.G. and Z.T.; the characterizations, catalyst evaluation, and analysis were done by Z.G., Z.T., R.V., and J.K.; the manuscript was written and amended by Z.G. and Z.T. All authors have read and agreed to the published version of the manuscript.

Funding: This publication is a result of the project CATAMARAN, Reg. No. CZ.02.1.01/0.0/0.0/16_013/0001801, which has been co-financed by the European Union from the European Regional Development Fund through the operational program, Research, Development, and Education. This project has also been financially supported by the Ministry of Industry and Trade of the Czech Republic, which has been providing institutional support for the long-term conceptual development of research organization. The project CATAMARAN has been integrated into the National Sustainability Programme I of the Ministry of Education, Youth and Sports of the Czech Republic (MEYS), through the project, Development of the UniCRE Centre (LO1606). The result was achieved using the infrastructure of the project Efficient Use of Energy Resources Using Catalytic Processes (LM2015039), which has been financially supported by MEYS within the targeted support of large infrastructures.

Conflicts of Interest: The authors declare no conflict of interest. The funders had no role in the design of the study; in the collection, analyses, or interpretation of data; in the writing of the manuscript, or in the decision to publish the results. 


\section{References}

1. Vosoughi, V.; Badoga, S.; Dalai, A.K.; Abatzoglou, N. Modification of mesoporous alumina as a support for cobalt-based catalyst in Fischer-Tropsch synthesis. Fuel Process. Technol. 2017, 162, 55-65. [CrossRef]

2. Pratt, J.W. A Fischer-Tropsch Synthesis Reactor Model Framework for Liquid Biofuels Production. SANDIA Report: SAND2012-7848, 2012. Available online: https://pdfs.semanticscholar.org/6093/ 1b3ffd88e3183156e132b694c50dc179833a.pdf (accessed on 15 May 2020).

3. Okoye-Chine, C.G.; Moyo, M.; Liu, X.; Hildebrandt, D. A critical review of the impact of water on cobalt-based catalysts in Fischer-Tropsch synthesis. Fuel Process. Technol. 2019, 192, 105-129. [CrossRef]

4. Vosoughi, V.; Badoga, S.; Dalai, A.K.; Abatzoglou, N. Effect of pretreatment on physicochemical properties and performance of multiwalled carbon nanotube supported cobalt catalyst for Fischer-Tropsch synthesis. Ind. Eng. Chem. Res. 2016, 55, 6049-6059. [CrossRef]

5. Odunsi, A.O.; O'Donovan, T.S.; Reay, D.A. Dynamic modeling of fixed-bed Fischer-Tropsch reactors with phase change material diluents. Chem. Eng. Technol. 2016, 39, 2066-2076. [CrossRef]

6. Gholami, Z.; Tišler, Z.; Rubáš, V. Recent advances in Fischer-Tropsch synthesis using cobalt-based catalysts: A review on supports, promoters, and reactors. Catal. Rev. 2020, 1-84. [CrossRef]

7. Gholami, Z.; Zabidi, N.A.M.; Gholami, F.; Ayodele, O.B.; Vakili, M. The influence of catalyst factors for sustainable production of hydrocarbons via Fischer-Tropsch synthesis. Rev. Chem. Eng. 2017, 33, 337-358. [CrossRef]

8. Li, J.; Yang, G.; Yoneyama, Y.; Vitidsant, T.; Tsubaki, N. Jet fuel synthesis via Fischer-Tropsch synthesis with varied 1-olefins as additives using $\mathrm{Co} / \mathrm{ZrO}_{2}-\mathrm{SiO}_{2}$ bimodal catalyst. Fuel 2016, 171, 159-166. [CrossRef]

9. Zhou, W.; Cheng, K.; Kang, J.; Zhou, C.; Subramanian, V.; Zhang, Q.; Wang, Y. New horizon in C1 chemistry: Breaking the selectivity limitation in transformation of syngas and hydrogenation of $\mathrm{CO}_{2}$ into hydrocarbon chemicals and fuels. Chem. Soc. Rev. 2019, 48, 3193-3228. [CrossRef]

10. Sartipi, S.; van Dijk, J.E.; Gascon, J.; Kapteijn, F. Toward bifunctional catalysts for the direct conversion of syngas to gasoline range hydrocarbons: H-ZSM-5 coated Co versus H-ZSM-5 supported Co. Appl. Catal. A Gen. 2013, 456, 11-22. [CrossRef]

11. Shi, D.; Faria, J.; Pham, T.N.; Resasco, D.E. Enhanced activity and selectivity of Fischer-Tropsch synthesis catalysts in water/oil emulsions. ACS Catal. 2014, 4, 1944-1952. [CrossRef]

12. Li, J.; He, Y.; Tan, L.; Zhang, P.; Peng, X.; Oruganti, A.; Yang, G.; Abe, H.; Wang, Y.; Tsubaki, N. Integrated tuneable synthesis of liquid fuels via Fischer-Tropsch technology. Nat. Catal. 2018, 1, 787-793. [CrossRef]

13. Sartipi, S.; Parashar, K.; Makkee, M.; Gascon, J.; Kapteijn, F. Breaking the Fischer-Tropsch synthesis selectivity: Direct conversion of syngas to gasoline over hierarchical Co/H-ZSM-5 catalysts. Catal. Sci. Technol. 2013, 3, 572-575. [CrossRef]

14. Choudhury, H.A.; Moholkar, V.S. Synthesis of liquid hydrocarbons by Fischer-Tropsch process using industrial iron catalyst. Int. J. Innovat. Res. Sci. Eng. Technol. 2013, 2, 3493-3499.

15. De La Ree, A.; Best, L.; Bradford, R.; Gonzalez-Arroyo, R.; Hepp, A. Fischer-Tropsch catalysts for aviation fuel production. In Proceedings of the 9th Annual International Energy Conversion Engineering Conference, San Diego, CA, USA, 31 July-3 August 2011; p. 5740.

16. Cano, F.M.; Gijzeman, O.; De Groot, F.; Weckhuysen, B. Manganese promotion in cobalt-based Fischer-Tropsch catalysis. Stud. Surf. Sci. Catal. 2004, 147, 271-276. [CrossRef]

17. Fan, G.; Li, F.; Evans, D.G.; Duan, X. Catalytic applications of layered double hydroxides: Recent advances and perspectives. Chem. Soc. Rev. 2014, 43, 7040-7066. [CrossRef]

18. Yu, J.; Wang, Q.; O'Hare, D.; Sun, L. Preparation of two dimensional layered double hydroxide nanosheets and their applications. Chem. Soc. Rev. 2017, 46, 5950-5974. [CrossRef]

19. Liao, P.; Zhang, C.; Zhang, L.; Yang, Y.; Zhong, L.; Wang, H.; Sun, Y. Higher alcohol synthesis via syngas over CoMn catalysts derived from hydrotalcite-like precursors. Catal. Today 2018, 311, 56-64. [CrossRef]

20. He, L.; Berntsen, H.; Ochoa-Fernández, E.; Walmsley, J.C.; Blekkan, E.A.; Chen, D. Co-Ni catalysts derived from hydrotalcite-like materials for hydrogen production by ethanol steam reforming. Top. Catal. 2009, 52, 206-217. [CrossRef]

21. Zhao, Q.; Ge, Y.; Fu, K.; Ji, N.; Song, C.; Liu, Q. Oxidation of acetone over Co-based catalysts derived from hierarchical layer hydrotalcite: Influence of $\mathrm{Co} / \mathrm{Al}$ molar ratios and calcination temperatures. Chemosphere 2018, 204, 257-266. [CrossRef] 
22. Hernández, W.Y.; Lauwaert, J.; Van Der Voort, P.; Verberckmoes, A. Recent advances on the utilization of layered double hydroxides (LDHs) and related heterogeneous catalysts in a lignocellulosic-feedstock biorefinery scheme. Green Chem. 2017, 19, 5269-5302. [CrossRef]

23. Kuśtrowski, P.; Chmielarz, L.; Bożek, E.; Sawalha, M.; Roessner, F. Acidity and basicity of hydrotalcite derived mixed $\mathrm{Mg}-\mathrm{Al}$ oxides studied by test reaction of $\mathrm{MBOH}$ conversion and temperature programmed desorption of $\mathrm{NH}_{3}$ and $\mathrm{CO}_{2}$. Mater. Res. Bull. 2004, 39, 263-281. [CrossRef]

24. Xu, Y.; Wang, Z.; Tan, L.; Yan, H.; Zhao, Y.; Duan, H.; Song, Y.-F. Interface engineering of high-energy faceted $\mathrm{Co}_{3} \mathrm{O}_{4} / \mathrm{ZnO}$ heterostructured catalysts derived from layered double hydroxide nanosheets. Ind. Eng. Chem. Res. 2018, 57, 5259-5267. [CrossRef]

25. Aider, N.; Touahra, F.; Bali, F.; Djebarri, B.; Lerari, D.; Bachari, K.; Halliche, D. Improvement of catalytic stability and carbon resistance in the process of $\mathrm{CO}_{2}$ reforming of methane by $\mathrm{CoAl}$ and $\mathrm{CoFe}$ hydrotalcite-derived catalysts. Int. J. Hydrog. Energy 2018, 43, 8256-8266. [CrossRef]

26. Maggi, R.; Martens, J.A.; Poncelet, G.; Grange, P.; Jacobs, P.A.; Delmon, B. Preparation of Catalysts VII; Elsevier Science: Amsterdam, the Netherlands, 1998.

27. Abelló, S.; Bolshak, E.; Montané, D. Ni-Fe catalysts derived from hydrotalcite-like precursors for hydrogen production by ethanol steam reforming. Appl. Catal. A Gen. 2013, 450, 261-274. [CrossRef]

28. Du, Y.-L.; Wu, X.; Cheng, Q.; Huang, Y.-L.; Huang, W. Development of Ni-based catalysts derived from hydrotalcite-like compounds precursors for synthesis gas production via methane or ethanol reforming. Catalysts 2017, 7, 70. [CrossRef]

29. Xiao, S.; Zhang, Y.; Gao, P.; Zhong, L.; Li, X.; Zhang, Z.; Wang, H.; Wei, W.; Sun, Y. Highly efficient Cu-based catalysts via hydrotalcite-like precursors for $\mathrm{CO}_{2}$ hydrogenation to methanol. Catal. Today 2017, 281, 327-336. [CrossRef]

30. Gao, P.; Xie, R.; Wang, H.; Zhong, L.; Xia, L.; Zhang, Z.; Wei, W.; Sun, Y. Cu/Zn/Al/Zr catalysts via phase-pure hydrotalcite-like compounds for methanol synthesis from carbon dioxide. J. CO2 Util. 2015, 11, 41-48. [CrossRef]

31. Tanios, C.; Bsaibes, S.; Gennequin, C.; Labaki, M.; Cazier, F.; Billet, S.; Tidahy, H.L.; Nsouli, B.; Aboukaïs, A.; Abi-Aad, E. Syngas production by the $\mathrm{CO}_{2}$ reforming of $\mathrm{CH}_{4}$ over $\mathrm{Ni}-\mathrm{Co}-\mathrm{Mg}-\mathrm{Al}$ catalysts obtained from hydrotalcite precursors. Int. J. Hydrog. Energy 2017, 42, 12818-12828. [CrossRef]

32. Izquierdo-Colorado, A.; Dębek, R.; Da Costa, P.; Gálvez, M.E. Excess-methane dry and oxidative reforming on Ni-containing hydrotalcite-derived catalysts for biogas upgrading into synthesis gas. Int. J. Hydrog. Energy 2018, 43, 11981-11989. [CrossRef]

33. Wierzbicki, D.; Baran, R.; Dębek, R.; Motak, M.; Grzybek, T.; Gálvez, M.E.; Da Costa, P. The influence of nickel content on the performance of hydrotalcite-derived catalysts in $\mathrm{CO}_{2}$ methanation reaction. Int. J. Hydrog. Energy 2017, 42, 23548-23555. [CrossRef]

34. Wang, L.; Cao, A.; Liu, G.; Zhang, L.; Liu, Y. Bimetallic CuCo nanoparticles derived from hydrotalcite supported on carbon fibers for higher alcohols synthesis from syngas. Appl. Surf. Sci. 2016, 360, 77-85. [CrossRef]

35. Liao, P.-Y.; Zhang, C.; Zhang, L.-J.; Yang, Y.-Z.; Zhong, L.-S.; Guo, X.-Y.; Wang, H.; Sun, Y.-H. Influences of $\mathrm{Cu}$ Content on the $\mathrm{Cu} / \mathrm{Co} / \mathrm{Mn} / \mathrm{Al}$ Catalysts Derived from Hydrotalcite-Like Precursors for Higher Alcohols Synthesis via Syngas. Acta Phys.-Chim. Sin. 2017, 33, 1672-1680. [CrossRef]

36. Forgionny, A.; Fierro, J.; Mondragón, F.; Moreno, A. Effect of Mg/Al Ratio on catalytic behavior of Fischer-Tropsch cobalt-based catalysts obtained from hydrotalcites precursors. Top. Catal. 2016, 59, 230-240. [CrossRef]

37. Jung, Y.-S.; Yoon, W.-L.; Seo, Y.-S.; Rhee, Y.-W. The effect of precipitants on $\mathrm{Ni}-\mathrm{Al}_{2} \mathrm{O}_{3}$ catalysts prepared by a co-precipitation method for internal reforming in molten carbonate fuel cells. Catal. Commun. 2012, 26, 103-111. [CrossRef] [PubMed]

38. Sadek, R.; Chalupka, K.A.; Mierczynski, P.; Rynkowski, J.; Gurgul, J.; Dzwigaj, S. Cobalt based catalysts supported on two kinds of beta zeolite for application in Fischer-Tropsch synthesis. Catalysts 2019, 9, 497. [CrossRef]

39. Kang, S.-H.; Ryu, J.-H.; Kim, J.-H.; Jang, I.H.; Kim, A.R.; Han, G.Y.; Bae, J.W.; Ha, K.-S. Role of ZSM5 distribution on $\mathrm{Co} / \mathrm{SiO}_{2}$ Fischer-Tropsch catalyst for the production of $\mathrm{C}_{5}-\mathrm{C}_{22}$ hydrocarbons. Energy Fuels 2012, 26, 6061-6069. [CrossRef] 
40. Kurian, M.; Thankachan, S.; Nair, D.S.; Aswathy, E.K.; Babu, A.; Thomas, A.; Krishna, K.T.B. Structural magnetic, and acidic properties of cobalt ferrite nanoparticles synthesised by wet chemical methods. J. Adv. Ceram. 2015, 4, 199-205. [CrossRef]

41. Qiao, J.; Wang, N.; Wang, Z.; Sun, W.; Sun, K. Porous bimetallic $\mathrm{Mn}_{2} \mathrm{Co}_{1} \mathrm{O}_{\mathrm{x}}$ catalysts prepared by a one-step combustion method for the low temperature selective catalytic reduction of $\mathrm{NO}_{x}$ with $\mathrm{NH}_{3}$. Catal. Commun. 2015, 72, 111-115. [CrossRef]

42. Liu, J.; Xiong, Z.B.; Zhou, F.; Lu, W.; Jin, J.; Ding, S.F. Promotional effect of $\mathrm{H}_{2} \mathrm{O}_{2}$ modification on the cerium-tungsten-titanium mixed oxide catalyst for selective catalytic reduction of $\mathrm{NO}$ with $\mathrm{NH}_{3}$. J. Phys. Chem. Solids 2018, 121, 360-366. [CrossRef]

43. Kim, S.; Jeon, S.G.; Lee, K.B. High-temperature $\mathrm{CO}_{2}$ sorption on hydrotalcite having a high $\mathrm{Mg} / \mathrm{Al} \mathrm{molar}$ ratio. ACS Appl. Mater. Interfaces 2016, 8, 5763-5767. [CrossRef]

44. Sun, L.; Yang, Y.; Ni, H.; Liu, D.; Sun, Z.; Li, P.; Yu, J. Enhancement of $\mathrm{CO}_{2}$ adsorption performance on hydrotalcites impregnated with alkali metal nitrate salts and carbonate salts. Ind. Eng. Chem. Res. 2020, 59, 6043-6052. [CrossRef]

45. Wang, H.; Liu, W.; Wang, Y.; Tao, N.; Cai, H.; Liu, J.; Lv, J. Mg-Al Mixed oxide derived from hydrotalcites prepared using the solvent-free method: A stable acid-base bifunctional catalyst for continuous-flow transesterification of dimethyl carbonate and ethanol. Ind. Eng. Chem. Res. 2020, 59, 5591-5600. [CrossRef]

46. Wiyantoko, B.; Kurniawati, P.; Purbaningtias, T.E.; Fatimah, I. Synthesis and characterization of hydrotalcite at different $\mathrm{Mg} / \mathrm{Al}$ molar ratios. Procedia Chem. 2015, 17, 21-26. [CrossRef]

47. Castaño-Robayo, M.-H.; Molina-Gallego, R.; Moreno-Guáqueta, S. Ethyl acetate oxidation over MnOx-CoOx. relationship between oxygen and catalytic activity. CT E F-Cienc. Tecnol. Futuro 2015, 6, 45-56.

48. Gong, K.; Lin, T.; An, Y.; Wang, X.; Yu, F.; Wu, B.; Li, X.; Li, S.; Lu, Y.; Zhong, L.; et al. Fischer-Tropsch to olefins over CoMn-based catalysts: Effect of preparation methods. Appl. Catal. A Gen. 2020, 592, 117414. [CrossRef]

49. Cui, M.; Hou, Y.; Zhai, Z.; Zhong, Q.; Zhang, Y.; Huang, X. Effects of hydrogen peroxide co-precipitation and inert $\mathrm{N}_{2}$ atmosphere calcination on CeZrLaNd mixed oxides and the catalytic performance used on $\mathrm{Pd}$ supported three-way catalysts. RSC Adv. 2019, 9, 8081-8090. [CrossRef]

50. Cai, L.-N.; Guo, Y.; Lu, A.-H.; Branton, P.; Li, W.-C. The choice of precipitant and precursor in the co-precipitation synthesis of copper manganese oxide for maximizing carbon monoxide oxidation. J. Mol. Catal. A Chem. 2012, 360, 35-41. [CrossRef] 